\title{
Exploring the Impact of a Mobile Health Solution for Postpartum Pelvic Floor Muscle Training: Pilot Randomized Controlled Feasibility Study
}

Sinéad Dufour ${ }^{1}$, PhD; Donna Fedorkow ${ }^{2}$, MD; Jessica Kun ${ }^{3}$, BSc, MSc; Shirley Xiaoxuan Deng ${ }^{4}$, BHSc; Qiyin Fang ${ }^{3,4}$, $\mathrm{PhD}$

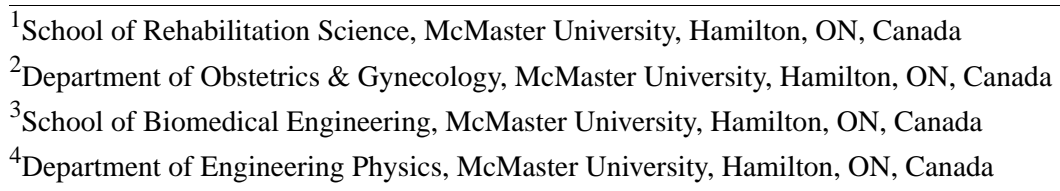

Corresponding Author:

Sinéad Dufour, $\mathrm{PhD}$

School of Rehabilitation Science

McMaster University

1280 Main Street West

Hamilton, ON, L8S 4K1

Canada

Phone: 19055259140

Email: sdufour@mcmaster.ca

\section{Abstract}

Background: The postpartum period is a vulnerable time for the pelvic floor. Early implementation of pelvic floor muscle exercises, appropriately termed as pelvic floor muscle training (PFMT), in the postpartum period has been advocated because of its established effectiveness. The popularity of mobile health (mHealth) devices highlights their perceived utility. The effectiveness of various mHealth technologies with claims to support pelvic floor health and fitness is yet to be substantiated through systematic inquiry.

Objective: The aim of this study was to determine the acceptability, feasibility, and potential effect on outcomes of an mHealth device purposed to facilitate pelvic floor muscle training among postpartum women.

Methods: A 16-week mixed methods pilot study was conducted to evaluate outcomes and determine aspects of acceptability and feasibility of an mHealth device. All participants received standardized examination of their pelvic floor muscles and associated instruction on the correct performance of PFMT. Those randomized to the iBall intervention received instructions on its use. Schedules for utilization of the iBall and PFMT were not prescribed, but all participants were informed of the standard established recommendation of PFMT, which includes 3 sets of 10 exercises, 3 to 4 times a week, for the duration of the intervention period. Quantitative data included the measurement of pelvic floor muscle parameters (strength, endurance, and coordination) following the PERFECT assessment scheme: Incontinence Impact Questionnaire scores and the Urogenital Distress Inventory (UDI-6) scores. Aspects of acceptability and feasibility were collected through one-to-one interviews. Interview transcripts were analyzed using Thorne's interpretive description approach.

Results: A total of 23 women with a mean age of 32.2 years were randomized to an intervention group ( $\mathrm{n}=13$ ) or a control group $(n=10)$. Both groups improved on all measures. The only statistically significant change was the UDI-6 score within both groups at 16 weeks compared with baseline. There was no statistically significant difference between the intervention group and control group on any outcomes. Most participants using the iBall $(\mathrm{n}=10,77 \%)$ indicated value in the concept of the mHealth solution. Technical difficulties $(n=10,77 \%)$, a cumbersome initiation process $(n=8,61 \%)$, and discomfort from the device $(n=8$, $61 \%)$ were reasons impeding intervention acceptability. Most participants $(n=17,74 \%)$ indicated that the initial assessment and training was more useful than the mHealth solution, a tenet that was echoed by all control group participants.

Conclusions: Our pilot study demonstrated the potential for mHealth solution-enhanced PFMT in the early postpartum period. Usability issues in hardware and software hindered feasibility and acceptance by the participants. Our findings can inform the redesign of mHealth solutions that may be of value if acceptability and feasibility issues can be overcome. 
Trial Registration: ClinicalTrials.gov NCT02865954; https://clinicaltrials.gov/ct2/show/NCT02865954

(JMIR Mhealth Uhealth 2019;7(7):e12587) doi: 10.2196/12587

\section{KEYWORDS}

postpartum; pelvic floor; mobile health; feasibility study; wireless technology; wearable technology; computer games; biofeedback

\section{Introduction}

The postpartum period is a vulnerable time for the pelvic floor [1]. Dysfunction of the pelvic floor musculature is associated with urinary and fecal incontinence, pelvic organ prolapse, and lumbopelvic pain [2-8]. Prevalence data vary; however, approximately $23 \%$ of postpartum women report either urinary or fecal incontinence [9].

Urinary incontinence represents the most prevalent issue and can be associated with reduced quality of life and mental health sequelae, such as depression and anxiety [10-14]. Stress urinary incontinence is defined as the involuntary loss of urine on effort or physical exertion, including coughing or sneezing [15]. It is associated with pregnancy, labor management, and birth and often manifests in the postpartum period [16-18].

Pelvic floor muscle training (PFMT) denotes individually tailored pelvic floor muscle rehabilitation programs aimed at restoring the fitness and function of the pelvic floor and associated deep core musculature. Early implementation of PFMT in the postpartum has been advocated based on 2 rigorously conducted reviews confirming prevention and correction of urinary incontinence through pelvic floor rehabilitation [19,20]. Research supports postpartum care to include basic evaluation of the pelvic floor musculature and associated education as well as feedback to ensure the correct performance of pelvic floor muscle exercises, namely PFMT $[21,22]$. PFMT can be effectively initiated with brief instruction through digital palpation of the pelvic floor muscles as associated feedback related to the muscle contraction completed [21]. It is established that, in the absence of providing adequate instruction and biofeedback, it is difficult for women to accurately perform pelvic floor muscle exercises [23,24]. Existing literature suggests that best practices for the prevention and management of pelvic floor dysfunction are not routinely implemented $[25,26]$. There is no universally accepted protocol for the initiation of PFMT in the postpartum period. This represents a research-practice gap in optimizing pelvic floor health in the postpartum period and beyond.

A proactive approach to pelvic health is needed as are strategies to overcome barriers contributing to this research-practice gap. Mobile health (mHealth) solutions may provide strategies to close the gap. mHealth solutions are defined by the World Health Organization [27] as the "medical and public health practice supported by mobile devices, such as mobile phones, patient monitoring devices, personal digital assistants, and other wireless devices" [27]. The current market for mHealth technologies is growing, including applications marketed for pelvic floor rehabilitation and fitness [28-31]. These mHealth technologies may represent innovative modalities to support pelvic floor muscle fitness. Claims and proposed benefits of these mHealth solutions, compared with standard care, are based on concepts and have not been substantiated by scientific investigation. Overall, the body of evidence on the effectiveness of mHealth technology is, in general, weak [32].

This pilot randomized controlled study aimed to evaluate the feasibility and acceptability of an mHealth solution (iBall) as a rehabilitation tool to support PFMT efforts in the early postpartum period. The iBall is a device that, upon insertion into the vaginal canal, can detect the strength and muscular endurance of pelvic floor muscles. The results are displayed in the accompanying mobile app that incorporates various training routines and gaming options. It aims to encourage both adherence to and improvement of outcomes of PFMT. Specifically, we sought to assess the feasibility, acceptability, and effectiveness of outcomes of an mHealth device (iBall) compared with PFMT instruction alone in the early postpartum period.

\section{Methods}

\section{Sample and Recruitment}

Women in the third trimester of pregnancy, attending local midwifery practices, were invited to participate in the study. Posters were used to facilitate recruitment. All initial study procedures took place in the early postpartum period (within the fourth trimester, the first 13 weeks postpartum). Following initial screening and confirmation of eligibility, participants were prospectively randomized to an mHealth-assisted PFMT intervention or PFMT instruction only (Figure 1). The study was approved by the Hamilton Integrated Research and Ethics Board.

\section{Intervention}

The iBall (ChunShuiTang Co Ltd) is an interactive mHealth device designed to facilitate PFMT. The iBall device is a US Federal Communications Commission-certified [33] and European Conformity-marked [34,35] device that, upon insertion into the vaginal canal, can detect the strength (power generation) and associated muscular endurance of pelvic floor muscles. Currently, iBall has been approved for consumer use in Europe and China. This information detected from the sensors within the device are transmitted via Bluetooth to a smartphone app that guides users in various exercise programs. The device is shown in Figure 1. It comprises 2 spherical compartments and a Bluetooth antenna for wireless communication with the smartphone. The whole device including the antenna is encapsulated in waterproof medical grade silicone casing. The battery and charging circuit are in the top spherical compartment with a waterproof charging port in the silicone encapsulation. 
Figure 1. The mHealth iBall device. The iBall device consists of a Bluetooth antenna that sits outside of the body and 2 spherical compartments containing a battery and biofeedback sensor that sits within the vaginal canal.
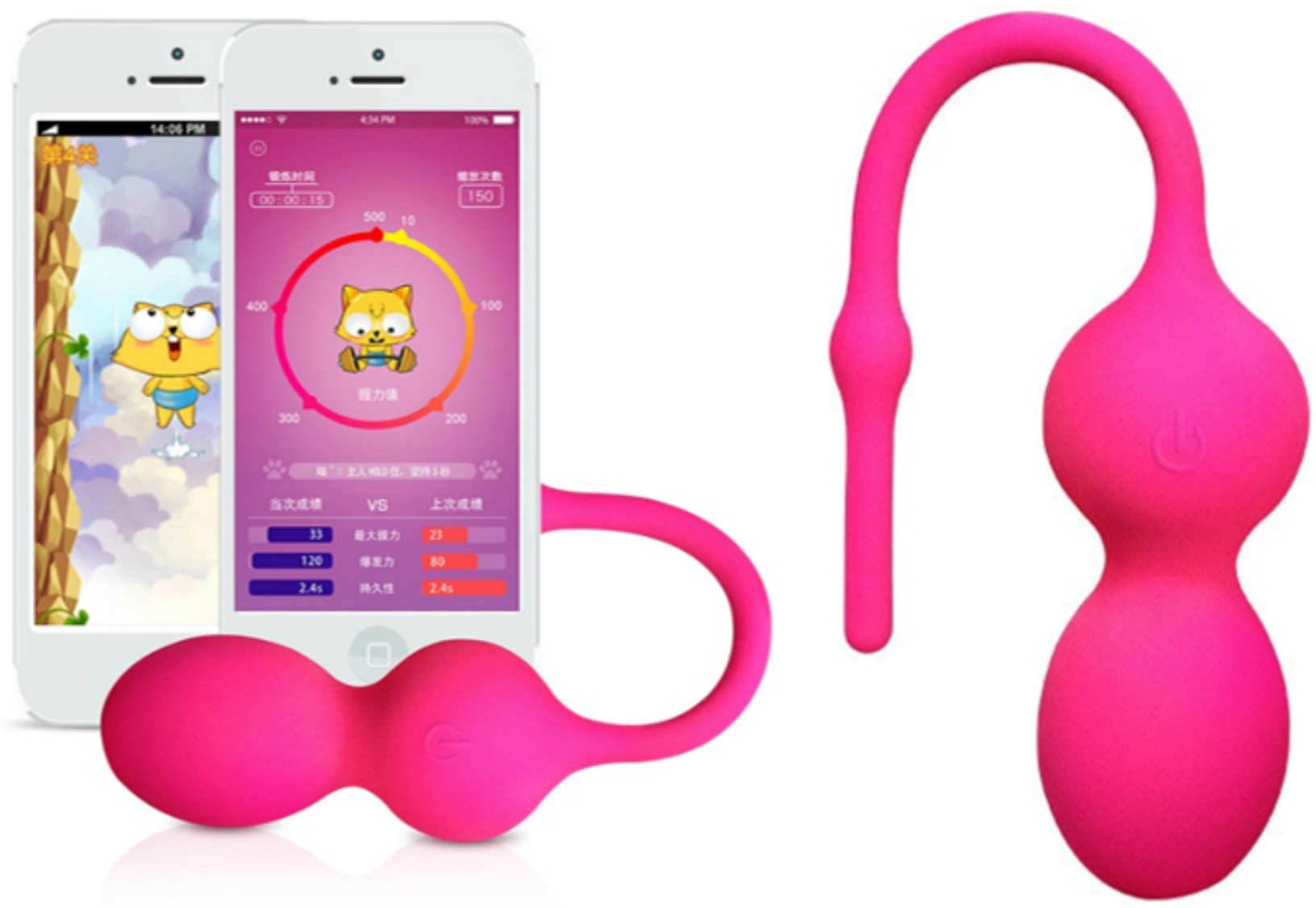

The sensor and biofeedback motors are in the bottom compartment, which also contains a power button under the silicone casing. The user can press and hold the power button to turn on/off the device. The antenna also serves as a handle to push in and pull out the device from the vaginal canal. In this study, each participant in the intervention group will receive an iBall device along with an already paired smartphone (iPhone 5e) with the mobile app installed and tested with the device. Both the iBall device and the smartphone were originally fully charged, and power will last a few days depending on usage level. They both require periodic charging by the participants at home during the study period. Once inserted, the user has several interactive games or activities to choose from on the corresponding app on their smartphone (Figure 2). Their progress can also be tracked, both as a score in the game and as a measure of power, endurance, repetitions, and contracting force (Figure 2).

These quantitative results are saved with a time stamp in the mobile app. The data can also be automatically uploaded to an encrypted cloud storage server through an opt in option. In this study, the participants have consented to upload their usage data for the study with the uploading feature enabled. Each user's study smartphone app has already been configured with a unique randomly generated user account and log-in credential. Only the research team has a securely saved lookup table linking the user account and the identity of the participants. The cloud-stored data can be downloaded as structured data files (in American Standard Code for Information Interchange format) for further analysis. The original consumer product has a Web-based profile function allowing the users to access their data on the cloud server and interact (by users' choice) with other users in a Web-based community. This feature is only available in Chinese and was permanently disabled in the clinical study version of the smartphone app. As a result, although the device and app have the capability of Web access to their usage data and interacting with other users, such functionalities were disabled in devices used in this study. The iBall device is currently marked as a consumer electronics gaming device. Some quantitative results (eg, power or contracting force) are not calibrated for absolute pressure measurements. The results of metrics obtained from the devices are not included in this study. 
Figure 2. The iBall App. Left: There are a number of activities that aid in engaging the pelvic floor. Right: The progress of the user can be tracked and monitored.

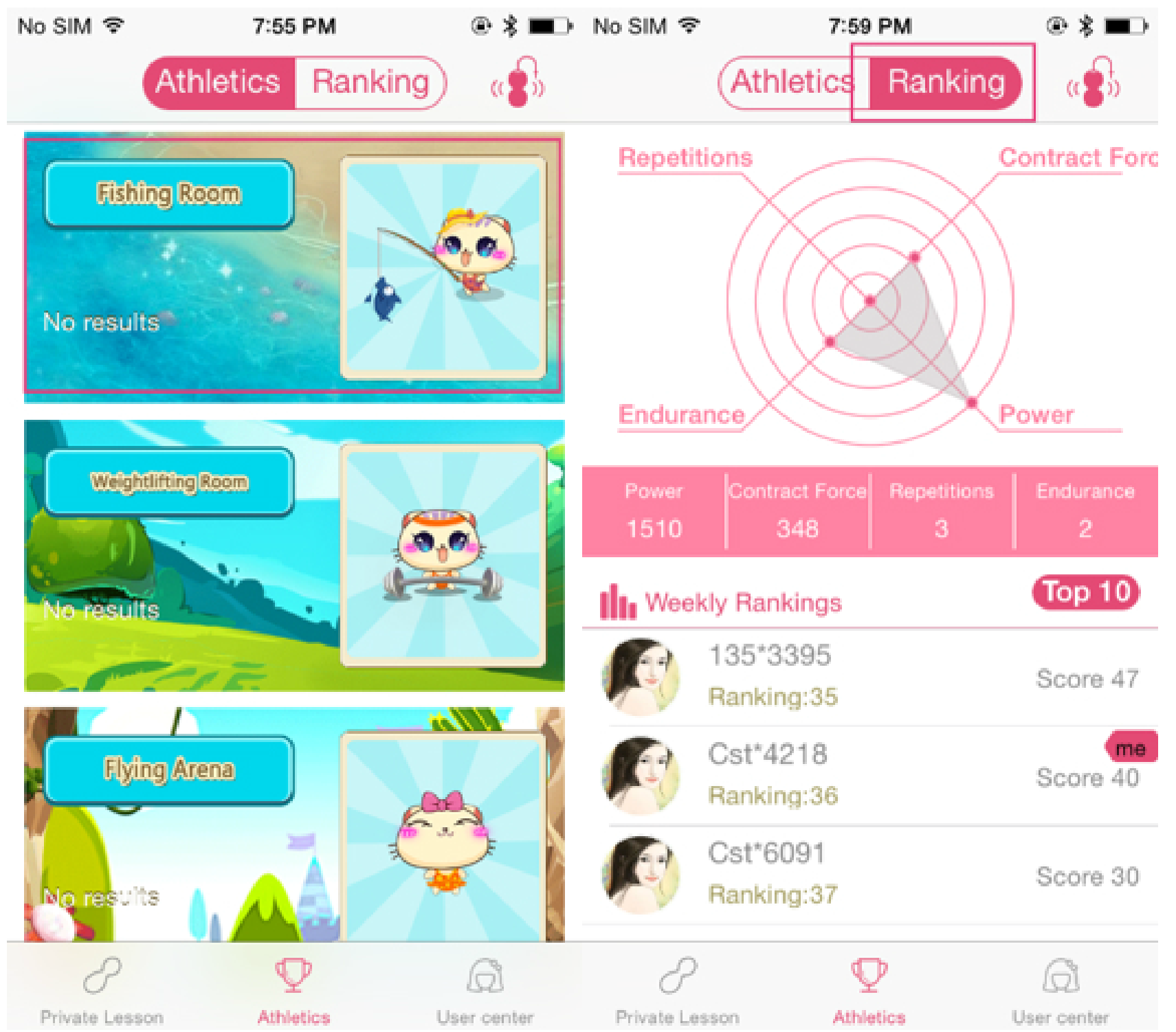

\section{Research Design}

This study was done in a 1:1 allocation ratio using random number assignments. Allocations were placed in sealed envelopes that were opened after the initial physical assessment at the time of randomization. Women having a vaginal or cesarean birth within 21 weeks of delivery were included. To maximize generalizability, the exclusions were made based on the individuals' inability to understand and read English and direction from their caregivers to not insert anything into their vagina.

An initial phone screening was conducted by a research assistant. Interested and eligible participants then met with a research assistant for further discussion and to obtain informed consent. The start time of the intervention took place in the early postpartum period, primarily during the fourth trimester (from week 6 postpartum to week 13 postpartum). The baseline characteristics of the participants have been provided in Table 1.

Subjects were then assessed by one of the expert assessors (SD and DF). The assessment included completion of 2 self-report outcome measures and a digital pelvic floor examination, inclusive of initiating PFMT by one of the 2 assessors. The 2 validated self-report measures that were administered were the Urogenital Distress Inventory (UDI-6) [36] and the Incontinence Impact Questionnaire (IIQ-7), which are shown in Table 2. The pelvic floor muscle examination followed the PERFECT scheme [8]. Clinically relevant changes in the PERFECT score was predetermined as an improvement of $20 \%$ based on previously published minimal clinical improvement thresholds (Table 3) [37].

Following assessment, subjects received their randomization allocation. Subjects randomized to the iBall group received additional instruction and training from the research assistant. Follow-up assessments were completed by the same assessors (SD and DF). A consistent process for assessment procedures including cueing during the pelvic floor muscle testing and instruction for the performance of pelvic floor exercises was established. All participants received instruction for the correct 
performance of pelvic floor muscle exercises via digital palpation. Schedules for utilization of the iBall and PFMT were not prescribed, but all participants were informed of the standard established recommendation of PFMT, which includes 3 sets of 10 exercises, 3 to 4 times a week, for duration of the intervention period [38]. Neither assessor was at any time, during the conduct of the study, aware of which group a subject was allocated.

Participants randomized to the intervention group received additional instruction on how to use the mHealth solution (iBall) by a research assistant. Participants were shown how to use the device and were familiarized with the associated app on the associated smartphone. Maintenance was informed as per manufacturers recommendations, which involved washing the device with warm water and a natural soap and storing it in the case it came in. Participants then used the device according to their own schedule (eg, when to exercise, frequency, and how long). The PFMT with iBall occurs within the context of playing a variety of games. Participants in the intervention group received a booster session, midway through the intervention period. This booster session consisted of an email sent by a research assistant reminding participants of features of the iBall and benefits of postpartum pelvic floor muscle exercise as a means of self-management support. The use of booster sessions to facilitate self-management support has been shown to be a useful procedure in rehabilitation interventions [40]. Quantitative measures were obtained at baseline and following 16 weeks of treatment. The duration of treatment was chosen based on the existing literature using 12 or more weeks as a reasonable therapeutic window [41,42]. As this was a pilot study, a convenient sample size of 23 was selected. This size appeared reasonable, given other comparison studies of PFMT [43].

Table 1. Baseline characteristics and participant demographics.

\begin{tabular}{|c|c|c|}
\hline Category & iBall, n (\%) & Control, n (\%) \\
\hline \multicolumn{3}{|l|}{ Age (years) } \\
\hline $26-30$ & $5(21.7)$ & $1(4.3)$ \\
\hline $31-36$ & $5(21.7)$ & $5(21.7)$ \\
\hline Unknown & $3(13.0)$ & $4(17.4)$ \\
\hline \multicolumn{3}{|l|}{ Number of deliveries } \\
\hline 1 & $6(26.1)$ & $1(4.3)$ \\
\hline 2 & $6(26.1)$ & $6(26.1)$ \\
\hline 3 & 0 & $1(4.3)$ \\
\hline 4 & $1(4.3)$ & 0 \\
\hline Unknown & 0 & $2(8.7)$ \\
\hline \multicolumn{3}{|l|}{ Weeks postpartum } \\
\hline$<7$ & $2(8.7)$ & $2(8.7)$ \\
\hline $7-14$ & $10(43.5)$ & $7(30.4)$ \\
\hline$>14$ & $1(4.3)$ & 0 \\
\hline \multicolumn{3}{|l|}{ PERFECT $^{\mathbf{a}}$ score } \\
\hline Power $(<3 / 5)$ & $2(15.4)$ & $4(40)$ \\
\hline Endurance $(<6 / 10)$ & $5(38.5)$ & $5(50)$ \\
\hline Repetition $(<6 / 10)$ & $7(53.8)$ & $7(70)$ \\
\hline Fast $(<6 / 10)$ & $6(46.2)$ & $6(60)$ \\
\hline Coordination (No) & $6(46.2)$ & $6(60)$ \\
\hline Timing (No) & $4(30.8)$ & $4(40)$ \\
\hline
\end{tabular}

${ }^{\mathrm{a}} \mathrm{PERFECT}$ is an acronym where $\mathrm{P}$ is power or pressure, $\mathrm{E}$ is endurance, $\mathrm{R}$ is repetitions, $\mathrm{F}$ is fast contractions, and ECT is every contraction timed. The scheme was developed to simplify and clarify pelvic floor muscle assessment [8]. 
Table 2. Baseline characteristics and participant demographics: urogenital distress inventory and Incontinence Impact Questionnaire scores.

\begin{tabular}{|c|c|c|c|c|}
\hline \multirow[t]{2}{*}{ Category } & \multicolumn{2}{|l|}{ iBall } & \multicolumn{2}{|c|}{ Control } \\
\hline & Mean & Range (SD) & Mean & Range (SD) \\
\hline Age (years) & 31 & $26-34(2.7)$ & 34 & $29-36(2.2)$ \\
\hline $\mathrm{UDI}^{\mathrm{a}}-6$ & 18.9 & $0-47(11.5)$ & 25.4 & $0-54(15.9)$ \\
\hline $\mathrm{IIQ}^{\mathrm{b}}-7$ & 8.1 & $0-50(15.6)$ & 7.4 & $0-28(11.4)$ \\
\hline
\end{tabular}

${ }^{a}$ UDI: Urogenital Distress Inventory.

bIIQ: Incontinence Impact Questionnaire.

Table 3. Operational definitions and psychometric properties of outcome measures.

\begin{tabular}{ll}
\hline Assessment, references, and description of procedure & Interpretation \\
\hline UDI $^{\mathbf{a}} \mathbf{- 6}[\mathbf{3 6}]$ & \\
$\begin{array}{l}\text { Designed to assess the degree to which symptoms associated with incon- } \\
\text { tinence are troubling. The weight of accumulated evidence suggests that }\end{array}$ & self-rated severity.
\end{tabular}
the both the UDI long and short forms are validated.

\section{IIQ ${ }^{b}-7[36]$}

Designed to assess the impact of urinary incontinence on activities and emotions. The weight of accumulated evidence suggests that both the UDI long and short forms are validated.

\section{PERFECT score [8,39]}

$\mathrm{P}$ - power, using the Modified Oxford grading scale: 0-no contraction; 1-flicker; 2-weak squeeze, no lift; 3-fair squeeze, definite lift; 4-good squeeze with lift; 5 -strong squeeze with a lift; Positive test: $<4 / 5$

E-endurance, the time (in seconds) that a maximum contraction can be sustained; Positive test: $<10$ seconds

$\mathrm{R}$-repetition, the number of repetitions of a maximum voluntary contraction; Positive test: $<10$ repetitions

$\mathrm{F}$ - fast contractions, the number of fast ( 1 second) maximum contractions; Positive test: $<10$ repetitions

ECT-timing-sustained voluntary contraction of the pelvic floor muscles with a cough; Positive test: no contraction of pelvic floor muscles before cough [35]
Symptoms scored according to self-rated severity.

Internal consistency $=0.84$; Correlation with long version $=0.95$

Pelvic floor muscle strength

Kappa $=0.48-0.77$

Pelvic floor muscle endurance

Pelvic floor muscle endurance

Pelvic floor muscle responsiveness

Pelvic floor muscle coordination

Kappa $=0.14-0.53$
Kappa $=0.17-0.56$

Kappa $=0.48-0.77$

Kappa $=0.29-0.65$

${ }^{\mathrm{a}} U D I$ : Urogenital Distress Inventory.

${ }^{\mathrm{b}} \mathrm{IIQ}$ : Incontinence Impact Questionnaire.

All quantitative data were inputted into an Excel spreadsheet (version 2017) for analysis. Data were cleaned and checked for out-of-range values, skip pattern problems, and duplicates. Tests of normality were completed to determine appropriateness of statistical methods. Analyses were performed using an intention-to-treat basis. All statistical tests used 2-sided tests at the .05 level of significance. Descriptive analyses of participants' characteristics and feasibility of the intervention were expressed as a mean (standard deviation) or median (minimum-maximum) for continuous variables and count (percent) for categorical variables. Changes in outcomes over time were examined using paired $t$ tests for continuous variables and Fischer exact test for categorical variables.

In addition to repeating all baseline assessments, the postintervention assessments required additional data collection from both groups to determine the implementation outcomes of acceptability and feasibility of the intervention (Table 4).
The PFMT instruction only (control) group answered 3 self-administered questions.

1. Are you having any problems that you attribute to your pelvic floor needing rehabilitation (urinary or fecal incontinence, pelvic or lower back pain, painful intercourse, or pelvic pressure)?

2. Consider the last few months since your baseline assessment, is there anything that you think might have been useful to enhance your physical postpartum recovery?

3. If you had the opportunity to use a mobile health app designed to assist with PFMT (eg, iBall), would you want to try it?

Aspects of acceptability and feasibility were collected through one-to-one interviews. Interviews were conducted by one of the 2 study assessors (SD and SD); transcripts were analyzed using Thorne's interpretive description approach [44]. The larger 
purpose of this study was to seek an in-depth understanding of the mHealth solution studied, such as to inform clinical practice. This included assessment of the interventions' perceived effects, barriers, and facilitators to implementation and strategies to implementing this approach to care. Participants in the intervention group were asked the following questions:

1. Tell me about your experiences using the iBall device?

2. What aspects of iBall were the most useful or helpful?
3. Which aspects of iBall were least useful or helpful?

4. Are there any changes you would make to the iBall device or app?

5. If you had to explain iBall to a friend, what would you say?

6. Would you recommend it to a friend? Why or why not?

7. Do you plan on continuing to use iBall at this time? Why or why not?

8. Would you consider using iBall again in the future?

Table 4. Description of implementation outcomes.

\begin{tabular}{lll}
\hline Outcome & Measures & Mode of analysis \\
\hline $\begin{array}{l}\text { Acceptability: A willingness to receive the of- } \\
\text { fered intervention }\end{array}$ & $\begin{array}{l}\text { Enrollment rate; attrition/retention rate; engage- } \\
\text { ment/adherence rate }\end{array}$ & $\begin{array}{l}\text { Research log: enrollment, follow-up and engage- } \\
\text { ment tracking; analytics data; qualitative data }\end{array}$ \\
$\begin{array}{lll}\text { Feasibility: The capability to carry out interven- } \\
\text { tion activities }\end{array}$ & $\begin{array}{l}\text { Training of the interventionists; delivery of the } \\
\text { program; outcome capture; perceptions of barri- }\end{array}$ & $\begin{array}{l}\text { Research log: enrollment, follow-up and engage- } \\
\text { ers and facilitators }\end{array}$ \\
\hline
\end{tabular}

Content analysis, following interpretive qualitative description, of participants' responses was used to analyze the qualitative data. The investigators systematically reviewed all transcripts and inductively generated a list of codes by hand. The codes were grouped into categories and then collapsed further into broader themes [44].

\section{Results}

A total of 23 participants were enrolled in the study. Of them, 13 were randomized to the iBall intervention group and 10 to the PFMT instruction group. Baseline characteristics were similar for both groups (Table 1).

Regarding implementation outcomes, which is the primary focus of this study, we found that, in its current form, the mHealth solution was not found to be superior to basic PFMT instruction alone (Table 5). A number of technical and logistical factors were found to hinder both the acceptability and feasibility of the mHealth intervention studied. A total of 15 categories emerged out of the qualitative analysis (Table 5), which were collapsed into 3 broader themes: (1) iBall represents an acceptable concept to support PFMT; (2) the steps involved in using iBall hinder the acceptability; (3) technology issues of this iBall are many but can be overcome.

There was no statistically significant difference between the groups for change scores (ie, 16-week score minus baseline score) for any measure (Table 6). The predetermined clinically relevant difference in PERFECT score of $20 \%$ was not achieved. Both the intervention and the standard care groups showed improvement on all outcome measures: PERFECT criteria, UDI-6, and the IIQ-7 at 16 weeks compared with baseline (Table 5). The UDI-6 score was the only outcome that achieved statistical significance in both groups.

Table 5. Pre- and postintervention measurements within group results.

\begin{tabular}{|c|c|c|c|c|c|c|c|c|}
\hline \multirow[t]{2}{*}{ Measurements } & \multicolumn{4}{|l|}{ iBall $(n=13)$} & \multicolumn{4}{|c|}{ Control $(n=10)$} \\
\hline & Pre (SD) & Post (SD) & $P$ value & $95 \% \mathrm{CI}$ & Pre (SD) & Post (SD) & $P$ value & $95 \% \mathrm{CI}$ \\
\hline UDI- $6^{\mathrm{a}, \mathrm{b}}$ & $18.9(11.5)$ & $7.3(5.9)$ & .009 & $-^{c}$ & $25.4(15.9)$ & $4.6(6.0)$ & .004 & - \\
\hline IIQ-7 ${ }^{\mathrm{b}, \mathrm{d}}$ & $8.1(15.6)$ & $3.7(5.6)$ & 1.00 & - & $7.4(11.4)$ & $3.2(8.4)$ & .36 & - \\
\hline \multicolumn{9}{|l|}{ PERFECT score ${ }^{\mathrm{e}}$} \\
\hline Power $<3 / 5$ & $2(1.3)$ & $0(1.5)$ & .27 & $0.03-5.25$ & $2(0.7)$ & $1(0.7)$ & .24 & $0.02-4.91$ \\
\hline Endurance $<6 / 10$ & $2(2.7)$ & $0(1.9)$ & .27 & $0.03-5.25$ & $0(0.7)$ & $0(1.4)$ & $>.99$ & $0.05-20.83$ \\
\hline Repetitions $<6 / 10$ & $7(3.1)$ & $2(3.7)$ & .07 & $0.01-1.32$ & $3(2.8)$ & $3(2.3)$ & .49 & $2.32-6.08$ \\
\hline Fast $<6 / 10$ & $5(2.7)$ & $7(2.9)$ & .051 & $0.02-6.35$ & $3(4.0)$ & $2(2.0)$ & .53 & $0.04-5.58$ \\
\hline Coordination: Yes & 6 & 6 & .33 & $0.05-2.77$ & 1 & 4 & .06 & $0.04-1.52$ \\
\hline Timing: Yes & 6 & 6 & 1.00 & $0.17-6.00$ & 1 & 4 & .20 & $0.01-2.82$ \\
\hline
\end{tabular}

${ }^{\mathrm{a}}$ UDI: Urogenital Distress Inventory.

${ }^{\mathrm{b}} P$ value calculated through the Mann-Whitney $U$ test.

${ }^{\mathrm{c}}$ Not applicable.

${ }^{\mathrm{d}}$ IIQ: Incontinence Impact Questionnaire.

$\mathrm{e}_{\mathrm{iBall}}$ and control PERFECT scores are mean difference values. $P$ values are calculated through Fisher exact test. 
Table 6. Postintervention measurements results between the iBall and the control groups.

\begin{tabular}{|c|c|c|c|c|}
\hline Measurements & iBall $(n=13)$, mean $(\mathrm{SD})$ & Control $(\mathrm{n}=10)$, mean $(\mathrm{SD})$ & $P$ value & $95 \% \mathrm{CI}$ \\
\hline UDI- $6^{\mathrm{a}, \mathrm{b}}$ & $7.3(5.9)$ & $4.6(6.0)$ & .28 & -8.29 to 2.89 \\
\hline IIQ-7 $7^{b, c}$ & $3.7(5.6)$ & $3.2(8.4)$ & .50 & -7.21 to 6.21 \\
\hline \multicolumn{5}{|l|}{ PERFECT score ${ }^{d}$} \\
\hline Power $>1$ & $2(0.7)$ & $4(1.3)$ & .09 & 0.06 to 3.17 \\
\hline Endurance $>2$ & $6(0.7)$ & $6(2.7)$ & .60 & 1.41 to 4.53 \\
\hline Repetitions $>2$ & $5(2.8)$ & $3(3.1)$ & $>.99$ & 0.32 to 11.8 \\
\hline Fast $>2$ & $7(4.0)$ & $4(2.7)$ & $>.99$ & 0.45 to 15.3 \\
\hline Coordination: Yes & 3 & 2 & $>.99$ & 1.95 to 11.5 \\
\hline Timing: Yes & 1 & 2 & .24 & 0.03 to 5.88 \\
\hline
\end{tabular}

${ }^{\mathrm{a} U D I}$ : Urogenital Distress Inventory.

${ }^{\mathrm{b}} P$ value calculated through the Mann-Whitney $U$ test.

${ }^{\mathrm{c}}$ IIQ: Incontinence Impact Questionnaire.

$\mathrm{d}_{\mathrm{iBall}}$ and control PERFECT scores are mean difference values. $P$ values are calculated through Fisher exact test.

\section{Discussion}

\section{Principal Findings}

The results of this randomized controlled pilot study do not support the use of the studied mHealth device in its current form when compared with PFMT instruction alone using the chosen quantitative measures. Although most participants indicated that the concept of the mHealth solution has potential, technical difficulties and a cumbersome setup were the primary themes that emerged impeding the intervention's acceptability. Only 2 of the 11 participants would recommend the mHealth solution to a friend, although 7 would consider recommending with modifications. Only 2 participants would consider using it again in the future (Table 7). Analytics data combined with interview data highlighted the lack of adherence to the intervention protocol. Technical issues related to the mHealth solution function hampered use. Consequently, we were unable to demonstrate increased motivation and adherence when using this mHealth solution.

Although there was improvement in both groups, there was no statistically significant difference between groups. The development of pelvic floor dysfunction involves a complex process involving a multifactorial etiology manifesting in the perinatal period [45]. We found that both groups achieved satisfactory pelvic floor health at the end of the 16-week intervention period. Level 1a evidence recommends the commencement of proper pelvic floor exercises in the early postpartum period, confirmed through a digital vaginal examination [21]. We implemented this recommendation across both control and intervention groups and both groups appeared to benefit.

The lack of implementation and adherence to PFMT protocols in the early postpartum period translates to a large proportion of women $(92 \%)$ continuing to have urinary incontinence 5 years postpartum if their incontinence was not resolved by 12 months postpartum [46]. Furthermore, $44.6 \%$ of women have been found to have incontinence 5 to 7 years postpartum [47]. These statistics are problematic considering that only a small proportion of women seek medical care for incontinence [48]. Our study results highlight the potential opportunity for enhanced pelvic floor muscle restoration and fitness development through more consistent implementation of postpartum PFMT.

Although the efficacy of PFMT is clearly established, the effect of adjunctive approaches is yet to demonstrate additional benefit. The International Consultation on Urinary Incontinence, a rigorous international committee-led review and analysis of the most up-to-date literature concluded that adjunctive pelvic floor muscle therapies such as biofeedback and electrical stimulation were not superior to supervised PFMT [49]. Many mHealth devices are available for use, and although they are designed to overcome some of the barriers inherent in traditional PFMT adjunctive technologies, few have been appropriately studied. A recent randomized controlled pilot study conducted to compare the Vibrance Kegel Device with a standard PFMT program suggested an added benefit to this mHealth solution [50].

The growing appeal of mobile solutions for health promotion and health care delivery can be attributed to the accessibility of the technology and the level of personalization that the technology enables [51]. Studies have shown that mHealth interventions have the potential to support successful management of chronic health conditions and associated health behavior change through (1) improving patient self-monitoring and management [52,53], (2) informing health care professionals of patients' health status [54,55], and (3) tailoring care and education to patient needs [56-58]. 
Table 7. Qualitative findings.

\begin{tabular}{|c|c|c|}
\hline Perspective & Agreement, $\mathrm{n}(\%)$ & Supporting quotes \\
\hline $\begin{array}{l}\text { The concept of a device to help reha- } \\
\text { bilitation of your pelvic floor through } \\
\text { biofeedback is good }\end{array}$ & $10(73)$ & $\begin{array}{l}\text { "As a busy mom I find I am too busy to be going to appointments, so this allowed me to } \\
\text { get the help I needed without going to appointments" (1001); "The concept is really good, } \\
\text { it's just that with a baby and a toddler time was my barrier" (1015); "I mean the premise } \\
\text { of having a game to strengthen the pelvic floor made it intriguing" (1005) }\end{array}$ \\
\hline The biofeedback was helpful & $4(31)$ & "When it was working it was helpful to have the feedback; I liked knowing how the pelvic \\
\hline
\end{tabular}
floor was working" (1023); "I liked how on the strengthening aspect graded the strength of the contraction, that was cool visual feedback" (1005)

The biofeedback was not helpful (in- $8(61)$ consistent/inaccurate)

Tracking my progress was a helpful $2(15)$ feature

Tracking my progress was not helpful (inconsistent/inaccurate)

Instructions were easy to follow and the purpose, clear

Instructions were not straight forward 7 (54) and the purpose, unclear

The device and app motivated me to do pelvic floor exercises (facilitator)

The device and app made it more difficult to do pelvic floor exercises (barrier)

Technical difficulties with the mHealth solution were an issue

The setup of the device and app was cumbersome (not new mom friendly)

The device was comfortable

The device was uncomfortable

Optional positioning of the device was an issue

The mHealth solution was helpful when combined with a pelvic floor examination

Instruction from the practitioner was more helpful than feedback from the device and app
"It didn't' reliably work so that really did not justify the effort in using it. It is not motivating using a device that is unreliable" (1002); "I was trying to squeeze as hard as I could and it just was not registering (1017)

"Seeing your score and being able to keep track of your score so that you were working towards something was motivating. The other part was being able to see other peoples scores, that helped to give you a sense of where you ranked in comparison to other people. That was motivating too or at least made it more enticing to want to play more" (1013)

"I found it really difficult to use it properly, some of the time it would say it was connected but then none of my resulted recorded" (1023); "I did find out that the results were not getting sent in for whatever reason so this was off putting and really made me not want to use it" (1011)

"it was pretty self-explanatory and I felt like the instructions I was given here at the beginning of the study were really clear and straight forward" (1001)

"It was a confusing because with the games there were no instructions, it took me multiple attempts to try to figure out what I was doing" (1005); "The instructions on the game could have been more clear, I never knew what the goal was or how long I should be playing for" (1017).

"In particular, I found the strength game really motivating" (1011); "I tried different games; the games were interesting they were like video games" (1010)

"The other thing I realized though is that when you have a baby it is a lot harder to use a device than it is to just do the kegels that were taught to you on your own" (1002); "The hassle of using the whole device was an issue, it was not as easy as just doing the [pelvic floor] exercises (1008); "The main barriers to using it was finding time to use it; needing privacy; and the cumbersome process to set it up" (1013)

"When I was trying to play the games I couldn't get any type of a score and it was frustrating because I didn't know if it was just a problem with the app or device or if I really was not getting any engagement of my pelvic floor" (1002); "The accuracy of how the device communicates with the definitely needs improvement" (1023)

"The fact that you have to set it up and lie down, get lubricant in order to use it - so set up and clean up doesn't mix well with the life of a busy mom who if constantly interrupted" (1015); "I was excited about it at first, but because it was too much work, a real hassle to get it set up, I didn't use it much" (1010)

"It was really easy to insert which was nice" (1011); "I found it comfortable and relatively user-friendly' (1015)

"I really haven't been using it - because it is big and frankly the idea of inserting it is not appealing, it took me 10 minutes to insert it" (1012); "I would make it [the device] more compact - it is big and not comfortable" (1008)

"but knowing the position of it - sometimes I wasn't sure if it was inserted too deep or too superficial" (1005); "Also, I did find slightly changing the position of the [device] really changed what the feedback indicated" (1023)

"It is not useful to have this without having the assessment and some discussion with an expert' (1017); "I don't think a device like this would have much values at all if you didn't also at least have some type of follow up in person" (1013)

"When I did the initial exam I found that really helpful here because I was never assessed like that before but I think I would have benefited from another appointment rather than just using the device" (1010); "I feel like I need proper pelvic floor physiotherapy as I feel like everything is too tight. so, I think that is really what I need, not a device like this" (1012) 
The iBall is a dynamic and interactive mHealth solution that has the capacity to enhance PFMT. With the capacity to provide biofeedback, record data, and track progress, iBall has the potential to increase motivation and adherence. Furthermore, the iBall device and smartphone app have the capability of remote storage of usage data for record keeping and additional analysis. The Web-based data feature is designed for further gamification apps. Owing to research ethics app constrains (Hamilton integrated Research Ethics Board has concerns regarding data access), the Web-based interaction features were disabled in this study. Nonetheless, based on experiences from gamification of wearable fitness devices [59], we foresee that such an interactive design feature will generally improve user motivation and adherence.

Our study has highlighted several aspects that are important for mHealth solutions to be acceptable and feasible for pelvic floor rehabilitation in the early postpartum period. Convenience, user friendliness, reliable technology, accurate biofeedback, and user progress tracking were identified as being important features (Table 7). Effective mHealth solutions require consideration of the understanding and capabilities of end users (patients and practitioners) to use the technology [60].

End user engagement throughout the design and development processes help ensure that mHealth solutions are acceptable and feasible by fitting within the end user's context [61]. Our study results emphasize the need of end user input in the design of mHealth solutions for pelvic floor muscle function/dysfunction. Acceptability and feasibility need to be established before testing the efficacy of potential pelvic floor rehabilitation mHealth solutions in fully powered randomized controlled trials (RCTs).

A significant limitation of this study is the small sample size. We had challenges with both recruitment and follow-up. Both contributed to poor feasibility. The small sample size confers caution to interpreting the statistical findings. As we did not conduct a priori sample size calculations, the results should be considered exploratory. We acknowledge possible ceiling effects related to the outcome measures. The low burden of pelvic floor dysfunction at baseline and limitations related to the UDI- 6 and
IIQ-7 in the postpartum period resulted in poor discriminatory powers of the measurements. The UDI-6 and IIQ-7 are well-established psychometrically sound self-report questionnaires that were developed for symptomatic patients and not healthy women in the early postpartum period. A recent review of 33 urogynecology questionnaires confirmed that none target postpartum women and that tools specific to this population are needed [62].

This pilot trial was designed to establish feasibility and identify issues for such mHealth technologies to be used in future clinical applications. Our results have led to the identification of several issues in the current device technologies that prevent it from being used in a large-scale trial and potential future clinical use. We also identified potential solutions that were mostly related to redesigning the device for clinical therapeutic use rather than recreational applications. Such changes are easy to implement with little technological barriers. For a future clinical trial, we expect a minor redesigning of the hardware, a major revision of the software (ie, the iBall app), and adjustments to the intervention protocol to reduce loss to follow-up and potentially improve adherence.

\section{Conclusions}

This pilot study has demonstrated that an mHealth solution may be useful in supporting PFMT. The concept of the mHealth solution was acceptable. However, several usability issues in hardware and software hindered its feasibility and acceptance as a rehabilitation tool by the participants. The results from this study affirm the potential for mHealth solutions to support PFMT in the early postpartum period, particularly with redesigning that allows for enhanced technical literacy and accurate biofeedback. We also affirmed the benefit of recommended PFMT alone, which recommends instruction of correct pelvic floor exercises through digital palpation early postpartum. Established acceptability and feasibility parameters are needed before testing potential pelvic floor rehabilitation mHealth solutions in future in fully powered RCTs to determine efficacy of this modality.

\section{Acknowledgments}

The iBall devices were provided by the manufacturer ChunShuiTang Co of Changzhou, China. This study is supported, in part, by the Natural Sciences and Engineering Research Council of Canada through an Undergraduate Summer Research Award to SXD and Discover Grant (365065 QF). QF holds the Canada Research Chair in Biophotonics.

\section{Conflicts of Interest}

None declared.

\section{Multimedia Appendix 1 \\ CONSORT - EHEALTH checklist (V 1.6.2).}

[PDF File (Adobe PDF File), 112KB-Multimedia Appendix 1]

\section{References}

1. Hannestad YS, Rortveit G, Sandvik H, Hunskaar S, Norwegian EPINCONT (Epidemiology of Incontinence in the County of Nord-Trøndelag) study. A community-based epidemiological survey of female urinary incontinence: the Norwegian 
EPINCONT study. Epidemiology of incontinence in the county of Nord-Trøndelag. J Clin Epidemiol 2000 Nov;53(11):1150-1157. [Medline: 11106889]

2. Dumoulin C, Hay-Smith EJ, Habée-Séguin GM. Pelvic floor muscle training versus no treatment, or inactive control treatments, for urinary incontinence in women. Cochrane Database Syst Rev 2014 May 14(5):CD005654. [doi: 10.1002/14651858.CD005654.pub3] [Medline: 24823491]

3. Dumoulin C, Hay-Smith J, Habée-Séguin GM, Mercier J. Pelvic floor muscle training versus no treatment, or inactive control treatments, for urinary incontinence in women: a short version Cochrane systematic review with meta-analysis. Neurourol Urodyn 2015 Apr;34(4):300-308. [doi: 10.1002/nau.22700] [Medline: 25408383]

4. National Collaborating Centre for Women's and Children's Health. Urinary Incontinence: The Management of Urinary Incontinence in Women, 2nd Edition. London: RCOG Press; 2013.

5. Shamliyan T, Wyman J, Kane RL. Effective Health Care Program, AHRQ. 2012. Nonsurgical Treatments for Urinary Incontinence in Adult Women: Diagnosis and Comparative Effectiveness URL: https://www.pcori.org/sites/default/files/ PCORI-Executive-Summary-NonSurgical-Treatment-of-Urinary-Incontinence-120716.pdf

6. Handa VL, Blomquist JL, Knoepp LR, Hoskey KA, McDermott KC, Muñoz A. Pelvic floor disorders 5-10 years after vaginal or cesarean childbirth. Obstet Gynecol 2011 Oct;118(4):777-784 [FREE Full text] [doi: 10.1097/AOG.0b013e3182267f2f] [Medline: 21897313]

7. Viktrup L, Summers KH, Dennett SL. Clinical practice guidelines on the initial assessment and treatment of urinary incontinence in women: a US focused review. Int J Gynaecol Obstet 2004 Jul;86(Suppl 1):S25-S37. [doi: 10.1016/j.ijgo.2004.05.008] [Medline: 15302565$]$

8. Dietz HP. Pelvic floor trauma in childbirth. Aust N Z J Obstet Gynaecol 2013 Jun;53(3):220-230. [doi: 10.1111/ajo.12059] [Medline: 23452259]

9. Solans-Domènech M, Sánchez E, Espuña-Pons M, Pelvic Floor Research Group (Grup de Recerca del Sòl Pelvià; GRESP). Urinary and anal incontinence during pregnancy and postpartum: incidence, severity, and risk factors. Obstet Gynecol 2010 Mar;115(3):618-628. [doi: 10.1097/AOG.0b013e3181d04dff] [Medline: 20177295]

10. Coyne KS, Kvasz M, Ireland AM, Milsom I, Kopp ZS, Chapple CR. Urinary incontinence and its relationship to mental health and health-related quality of life in men and women in Sweden, the United Kingdom, and the United States. Eur Urol 2012 Jan;61(1):88-95. [doi: 10.1016/j.eururo.2011.07.049] [Medline: 21831517]

11. Nilsson M, Margareta N, Lalos A, Ann L, Lalos O, Othon L. The impact of female urinary incontinence and urgency on quality of life and partner relationship. Neurourol Urodyn 2009;28(8):976-981. [doi: 10.1002/nau.20709] [Medline: 19229955]

12. Swithinbank LV, Abrams P. The impact of urinary incontinence on the quality of life of women. World J Urol 1999 Aug;17(4):225-229. [Medline: 10460405]

13. Melville JL, Delaney K, Newton K, Katon W. Incontinence severity and major depression in incontinent women. Obstet Gynecol 2005 Sep;106(3):585-592. [doi: 10.1097/01.AOG.0000173985.39533.37] [Medline: 16135592]

14. Smith AP. Female urinary incontinence and wellbeing: results from a multi-national survey. BMC Urol 2016 May 23;16(1):22 [FREE Full text] [doi: 10.1186/s12894-016-0140-z] [Medline: 27216251]

15. Bo K, Frawley HC, Haylen BT, Abramov Y, Almeida FG, Berghmans B, et al. An International Urogynecological Association (IUGA)/International Continence Society (ICS) joint report on the terminology for the conservative and nonpharmacological management of female pelvic floor dysfunction. Neurourol Urodyn 2017 Dec;36(2):221-244. [doi: 10.1002/nau.23107] [Medline: 27918122]

16. Glazener CM, Herbison GP, MacArthur C, Lancashire R, McGee MA, Grant AM, et al. New postnatal urinary incontinence: obstetric and other risk factors in primiparae. BJOG 2006 Feb;113(2):208-217 [FREE Full text] [doi: 10.1111/j.1471-0528.2005.00840.x] [Medline: 16412000 ]

17. Glazener CM, MacArthur C, Hagen S, Elders A, Lancashire R, Herbison GP, ProLong Study Group. Twelve-year follow-up of conservative management of postnatal urinary and faecal incontinence and prolapse outcomes: randomised controlled trial. BJOG 2014 Jan;121(1):112-120 [FREE Full text] [doi: 10.1111/1471-0528.12473] [Medline: 24148807]

18. Hunskaar S, Burgio K, Diokno A, Herzog AR, Hjälmås K, Lapitan MC. Epidemiology and natural history of urinary incontinence in women. Urology 2003 Oct;62(4 Suppl 1):16-23. [doi: 10.1016/S0090-4295(03)00755-6] [Medline: 14550833]

19. Woodley SJ, Boyle R, Cody JD, Mørkved S, Hay-Smith EJ. Pelvic floor muscle training for prevention and treatment of urinary and faecal incontinence in antenatal and postnatal women. Cochrane Database Syst Rev 2017 Dec 22;12:CD007471 [FREE Full text] [doi: 10.1002/14651858.CD007471.pub3] [Medline: 29271473]

20. Borello-France DF, Burgio KL, Goode PS, Markland AD, Kenton K, Balasubramanyam A, Urinary Incontinence Treatment Network. Adherence to behavioral interventions for urge incontinence when combined with drug therapy: adherence rates, barriers, and predictors. Phys Ther 2010 Oct;90(10):1493-1505 [FREE Full text] [doi: 10.2522/ptj.20080387] [Medline: 20671098]

21. Robert M, Ross S. No 186-conservative management of urinary incontinence. J Obstet Gynaecol Can 2018 Feb;40(2):e119-e125. [doi: 10.1016/j.jogc.2017.11.027] [Medline: 29447716] 
22. Boyle R, Hay-Smith EJ, Cody JD, Mørkved S. Pelvic floor muscle training for prevention and treatment of urinary and fecal incontinence in antenatal and postnatal women: a short version Cochrane review. Neurourol Urodyn 2014 Mar;33(3):269-276. [doi: 10.1002/nau.22402] [Medline: 23616292]

23. Bump RC, Hurt WG, Fantl JA, Wyman JF. Assessment of Kegel pelvic muscle exercise performance after brief verbal instruction. Am J Obstet Gynecol 1991 Aug;165(2):322-7; discussion 327. [doi: 10.1016/0002-9378(91)90085-6] [Medline: 1872333]

24. Vermandel A, de Wachter S, Beyltjens T, D'Hondt D, Jacquemyn Y, Wyndaele JJ. Pelvic floor awareness and the positive effect of verbal instructions in 958 women early postdelivery. Int Urogynecol J 2015 Feb;26(2):223-228. [doi: 10.1007/s00192-014-2483-x] [Medline: 25062656]

25. Shaw C, Atwell C, Wood F, Brittain K, Williams K. A qualitative study of the assessment and treatment of incontinence in primary care. Fam Pract 2007 Oct;24(5):461-467. [doi: 10.1093/fampra/cmm041] [Medline: 17670805]

26. Wagg A, Duckett J, McClurg D, Harari D, Lowe D. To what extent are national guidelines for the management of urinary incontinence in women adhered? Data from a national audit. BJOG 2011 Dec;118(13):1592-1600 [FREE Full text] [doi: 10.1111/j.1471-0528.2011.03100.x] [Medline: 21895954]

27. mHealth: New Horizons For Health Through Mobile Technologies. Second Global Survey on eHealth. Geneva, Switzerland: World Health Organization; 2011.

28. Nunes EF, Sampaio LM, Biasotto-Gonzalez DA, Nagano RC, Lucareli PR, Politti F. Biofeedback for pelvic floor muscle training in women with stress urinary incontinence: a systematic review with meta-analysis. Physiotherapy 2019 Dec;105(1):10-23. [doi: 10.1016/j.physio.2018.07.012] [Medline: 30686479]

29. Becker S, Miron-Shatz T, Schumacher N, Krocza J, Diamantidis C, Albrecht UV. mHealth 2.0: experiences, possibilities, and perspectives. JMIR Mhealth Uhealth 2014 May 16;2(2):e24 [FREE Full text] [doi: 10.2196/mhealth.3328] [Medline: 25099752]

30. Barbieri M, Andreoni G. mHealth market exploitation through the analysis of the related intellectual property rights. In: Andreoni G, Perego P, Frumento E, editors. m_Health Current and Future Applications. Munich: Springer; 2019:19-34.

31. Vukovic V, Favaretti C, Ricciardi W, de Waure C. Health technology assessment evidence on e-health/m-health technologies: evaluating the transparency and thoroughness. Int J Technol Assess Health Care 2018 Jan;34(1):87-96. [doi: 10.1017/S0266462317004512] [Medline: 29455685]

32. Powell AC, Landman AB, Bates DW. In search of a few good apps. J Am Med Assoc 2014 May 14;311(18):1851-1852. [doi: 10.1001/jama.2014.2564] [Medline: 24664278]

33. Federal Communications Commission. 2014. Equipment Authorization URL: https://www.fcc.gov/engineering-technology/ laboratory-division/general/equipment-authorization [accessed 2019-06-27]

34. EUR-Lex: EU Law. 2004. Directive 2004/108/EC of the European Parliament and of the Council URL: https://eur-lex. europa.eu/LexUriServ/LexUriServ.do?uri=OJ:L:2004:390:0024:0037:EN:PDF

35. EUR-Lex: EU law. 2011. Directive 2011/65/EU of the European Parliament and of the Council URL: https://eur-lex. europa.eu/LexUriServ/LexUriServ.do?uri=OJ:L:2011:174:0088:0110:EN:PDF

36. Harvey MA, Kristjansson B, Griffith D, Versi E. The incontinence impact questionnaire and the urogenital distress inventory: a revisit of their validity in women without a urodynamic diagnosis. Am J Obstet Gynecol 2001 Jul;185(1):25-31. [doi: 10.1067/mob.2001.116369] [Medline: 11483899$]$

37. Salottolo K, Stahl E. Minimal clinically important improvement response in patients with severe osteoarthritis of the knee: short report from a survey of clinicians. J Orthop 2018 Jun;15(2):424-425 [FREE Full text] [doi: 10.1016/j.jor.2018.03.034] [Medline: 29881169]

38. Mørkved S, B $\varnothing$ K. Effect of pelvic floor muscle training during pregnancy and after childbirth on prevention and treatment of urinary incontinence: a systematic review. Br J Sports Med 2014 Feb;48(4):299-310. [doi: 10.1136/bjsports-2012-091758] [Medline: 23365417]

39. Slieker-ten HM, Pool-Goudzwaard AL, Eijkemans MJ, Steegers-Theunissen RP, Burger CW, Vierhout ME. Face validity and reliability of the first digital assessment scheme of pelvic floor muscle function conform the new standardized terminology of the International Continence Society. Neurourol Urodyn 2009;28(4):295-300. [doi: 10.1002/nau.20659] [Medline: 19090583]

40. Dufour SP, Graham S, Friesen J, Rosenblat M, Rous C, Richardson J. Physiotherapists supporting self-management through health coaching: a mixed methods program evaluation. Physiother Theory Pract 2015 Jan;31(1):29-38. [doi: 10.3109/09593985.2014.930769] [Medline: 24983454]

41. Kashanian M, Ali SS, Nazemi M, Bahasadri S. Evaluation of the effect of pelvic floor muscle training (PFMT or Kegel exercise) and assisted pelvic floor muscle training (APFMT) by a resistance device (Kegelmaster device) on the urinary incontinence in women: a randomized trial. Eur J Obstet Gynecol Reprod Biol 2011 Nov;159(1):218-223. [doi: 10.1016/j.ejogrb.2011.06.037] [Medline: 21741151]

42. Kargar JM, Talebizadeh M, Mirzaei M. The effect of pelvic muscle exercises on urinary incontinency and self-esteem of elderly females with stress urinary incontinency, 2013. Glob J Health Sci 2014 Sep 28;7(2):71-79 [FREE Full text] [doi: 10.5539/gjhs.v7n2p71] [Medline: 25716389] 
43. Harvey MA. Pelvic floor exercises during and after pregnancy: a systematic review of their role in preventing pelvic floor dysfunction. J Obstet Gynaecol Can 2003 Jun;25(6):487-498. [doi: 10.1016/S1701-2163(16)30310-3] [Medline: 12806450]

44. Thorne S. Interpretive Description: Qualitative Research for Applied Practice. Second Edition. London: Routledge; 2016.

45. Groutz A, Rimon E, Peled S, Gold R, Pauzner D, Lessing JB, et al. Cesarean section: does it really prevent the development of postpartum stress urinary incontinence? A prospective study of 363 women one year after their first delivery. Neurourol Urodyn 2004;23(1):2-6. [doi: 10.1002/nau.10166] [Medline: 14694448]

46. Viktrup L, Lose G. Lower urinary tract symptoms 5 years after the first delivery. Int Urogynecol J Pelvic Floor Dysfunct 2000 Dec;11(6):336-340. [doi: 10.1007/s001920070002] [Medline: 11147740 ]

47. Fritel X, Fauconnier A, Levet C, Bénifla JL. Stress urinary incontinence 4 years after the first delivery: a retrospective cohort survey. Acta Obstet Gynecol Scand 2004 Oct;83(10):941-945 [FREE Full text] [doi:

10.1111/j.0001-6349.2004.00457.x] [Medline: 15453890$]$

48. Hannestad YS, Rortveit G, Hunskaar S. Help-seeking and associated factors in female urinary incontinence. The Norwegian EPINCONT study. Epidemiology of incontinence in the county of Nord-Trøndelag. Scand J Prim Health Care 2002 Jun;20(2):102-107. [doi: 10.1080/pri.20.2.102.107] [Medline: 12184708]

49. Abrams P, Cardozo L, Wagg A, Wein A, editors. Incontinence. Sixth Edition. Bristol, UK: International Continence Society; 2017.

50. Ong TA, Khong SY, Ng KL, Ting JR, Kamal N, Yeoh WS, et al. Using the vibrance Kegel device with pelvic floor muscle exercise for stress urinary incontinence: a randomized controlled pilot study. Urology 2015 Sep;86(3):487-491 [FREE Full text] [doi: 10.1016/j.urology.2015.06.022] [Medline: 26142713]

51. Akter S, Ray P. mHealth - an ultimate platform to serve the unserved. Yearb Med Inform 2010:94-100. [doi: 10.1055/s-0038-1638697] [Medline: 20938579]

52. Kollmann A, Riedl M, Kastner P, Schreier G, Ludvik B. Feasibility of a mobile phone-based data service for functional insulin treatment of type 1 diabetes mellitus patients. J Med Internet Res 2007 Dec 31;9(5):e36 [FREE Full text] [doi: $\underline{10.2196 / j m i r .9 .5 . e 36}$ ] [Medline: 18166525]

53. Walters DL, Sarela A, Fairfull A, Neighbour K, Cowen C, Stephens B, et al. A mobile phone-based care model for outpatient cardiac rehabilitation: the care assessment platform (CAP). BMC Cardiovasc Disord 2010 Jan 28;10:5 [FREE Full text] [doi: 10.1186/1471-2261-10-5] [Medline: 20109196]

54. Villalba E, Salvi D, Ottaviano M, Peinado I, Arredondo MT, Akay A. Wearable and mobile system to manage remotely heart failure. IEEE Trans Inf Technol Biomed 2009 Nov;13(6):990-996. [doi: 10.1109/TITB.2009.2026572] [Medline: 19643715]

55. Rubel P, Fayn J, Nollo G, Assanelli D, Li B, Restier L, et al. Toward personal eHealth in cardiology. Results from the EPI-MEDICS telemedicine project. J Electrocardiol 2005 Oct;38(4 Suppl):100-106. [doi: 10.1016/j.jelectrocard.2005.06.011] [Medline: 16226083 ]

56. Kearney N, McCann L, Norrie J, Taylor L, Gray P, McGee-Lennon M, et al. Evaluation of a mobile phone-based, advanced symptom management system (ASyMS) in the management of chemotherapy-related toxicity. Support Care Cancer 2009 Apr;17(4):437-444. [doi: 10.1007/s00520-008-0515-0] [Medline: 18953579]

57. Larsen ME, Rowntree J, Young AM, Pearson S, Smith J, Gibson OJ, et al. Chemotherapy side-effect management using mobile phones. Conf Proc IEEE Eng Med Biol Soc 2008;2008:5152-5155. [doi: 10.1109/IEMBS.2008.4650374] [Medline: 19163877]

58. Kim J, Kim S, Kim H, Kim K, Lee C, Yang S, et al. Acceptability of the consumer-centric u-health services for patients with chronic obstructive pulmonary disease. Telemed J E Health 2012 Jun;18(5):329-338. [doi: 10.1089/tmj.2011.0140] [Medline: 22510084]

59. Stragier J, Abeele MV, Mechant P, de Marez L. Understanding persistence in the use of online fitness communities: comparing novice and experienced users. Comput Human Behav 2016 Nov;64:34-42. [doi: 10.1016/j.chb.2016.06.013]

60. Malinowsky C, Nygård L, Kottorp A. Using a screening tool to evaluate potential use of e-health services for older people with and without cognitive impairment. Aging Ment Health 2014;18(3):340-345. [doi: 10.1080/13607863.2013.832731] [Medline: 24548108]

61. Levac D, Colquhoun H, O'Brien KK. Scoping studies: advancing the methodology. Implement Sci 2010 Sep 20;5:69 [FREE Full text] [doi: 10.1186/1748-5908-5-69] [Medline: 20854677]

62. Zuchelo LT, Bezerra IM, da Silva AT, Gomes JM, Soares JJ, Chada BE, et al. Questionnaires to evaluate pelvic floor dysfunction in the postpartum period: a systematic review. Int J Womens Health 2018;10:409-424 [FREE Full text] [doi: 10.2147/IJWH.S164266] [Medline: 30123009]

\section{Abbreviations}

IIQ: Incontinence Impact Questionnaire

mHealth: mobile health

PFMT: pelvic floor muscle training

RCT: randomized controlled trial 
UDI: Urogenital Distress Inventory

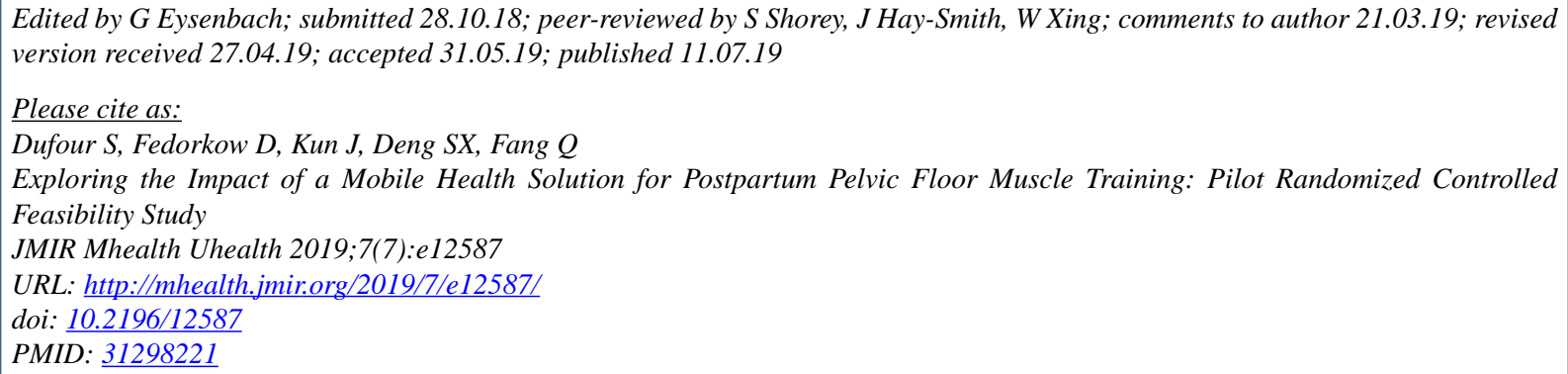

CSinéad Dufour, Donna Fedorkow, Jessica Kun, Shirley Xiaoxuan Deng, Qiyin Fang. Originally published in JMIR Mhealth and Uhealth (http://mhealth.jmir.org), 11.07.2019. This is an open-access article distributed under the terms of the Creative Commons Attribution License (https://creativecommons.org/licenses/by/4.0/), which permits unrestricted use, distribution, and reproduction in any medium, provided the original work, first published in JMIR mhealth and uhealth, is properly cited. The complete bibliographic information, a link to the original publication on http://mhealth.jmir.org/, as well as this copyright and license information must be included. 